Author's accepted manuscript.

The published version of this paper is available online at:

http://dx.doi.org/10.5750/ejpch.v5i3.1298

Please cite this paper as:

Webster, R.A.; Thompson, D.R.; Larkin, Derek; Mayou, R.A. and Martin, Colin R. (2017) Quality of life in a mixed ethnic population after myocardial infarction. European Journal of Person Centered Healthcare, 5(3) 295-299 


\title{
Quality of Life in a mixed ethnic population after myocardial infarction
}

\author{
Rosemary A. Webster RN BSc $\mathrm{MSc}^{\mathrm{a}}$, David R. Thompson RN BSc MA MBA PhD \\ FRCN FAAN FESC FCSANZ ${ }^{b}$, Derek Larkin BSc PhD ${ }^{\mathrm{C}}$, Richard A. Mayou MA \\ MPhil MB FRCP FRCPsych ${ }^{d}$ and Colin R. Martin RN BSc MSc MBA PhD ${ }^{\mathrm{e}}$
}

\author{
a Senior Nurse Educator, Cardio-respiratory Directorate, University Leicester NHS Hospitals Trust, Glenfield \\ General Hospital, Leicester, UK \\ b Professor of Nursing \& Director, Centre for the Heart and Mind, Australian Catholic University, Melbourne, \\ Australia \\ c Senior Lecturer, Department of Psychology, Edge Hill University, Lancashire, UK \\ d Professor of Psychiatry, Department of Psychiatry, University of Oxford, Oxford, UK \\ e Professor of Mental Health, School of Nursing, Bucks New University, Uxbridge, UK
}

\begin{abstract}
Background: Although South Asian people are a significant ethnic group at increased risk of coronary heart disease and high mortality rates and experience greater delays with respect to diagnosis, referral and treatment, comparatively little is known about their quality of life during recovery from a myocardial infarction.

Objectives: We sought to determine and compare the impact of ethnicity on quality of life after myocardial infarction (MI) in a mixed ethnic population (South Asian and white people) in the UK.

Methods: A 2x2 mixed-group design with repeated measures on the second factor. The independent variables were ethnic group (white/South Asian) and time since MI (2 weeks/3 months). The dependent variables were the subscale scores on the Short-Form 36-item health survey (SF-36) and the Hospital Anxiety and Depression Scale (HADS).

Results: At 2 weeks, significant differences were observed between groups on 5 of the 8 SF-36 subscale domain scores, with the white group reporting higher quality of life. Significant improvement in reported quality of life occurred in both groups over time on all domains of the SF-36, except bodily pain. There was a significantly greater improvement in favour of the white group for the role-physical domain. There was no significant difference between groups in terms of anxiety or depression at 2 weeks. Both groups showed a significant reduction in anxiety and depression by 3 months, but the degree of reduction was not significantly different between them. At 3 months, there was no significant difference between groups in terms of anxiety scores, but the South Asian group scored significantly higher on the depression scale.
\end{abstract}

Conclusions: South Asian people have significantly poorer quality of life than white people after MI. While both groups showed improvement over time, South Asian people reported significantly less improvement in physical role function and were more depressed at 3 months. Identifying the factors accounting for such differences is important to develop models of care for delivering the most effective and culturally-sensitive interventions to this group.

\section{Keywords}

Anxiety, culturally-sensitive care, depression, myocardial infarction, person-centered healthcare, Quality of Life, South Asian

\section{Introduction}

In the United Kingdom (UK) migrants from the Indian sub-continent (India, Pakistan and Bangladesh) and their children, as well as people from Kenya and Uganda descended from earlier immigrants from India, are a significant ethnic minority group. They are at increased risk of coronary heart disease and with other comorbidity and high mortality rates when compared to the white population [1-3]. Furthermore, the onset of coronary heart disease is earlier in South Asian people [4,5]. This may be indicative of ethnic differences in vascular remodelling [6,7]. There are also ethnic differences in healthcare- seeking behaviour and the way doctors manage South Asian people with chest pain [8-10]. South Asian people in the UK with myocardial infarction (MI) experience disproportionately greater delays with respect to diagnosis and treatment $[11,12]$, 
are less likely to use an ambulance [5], they wait longer for specialist referral [13,14] and are less likely to be treated with thrombolysis [15,16], or receive exercise testing [17] or angiography [18,19]. This is in addition to the many general barriers to accessing healthcare that face many South Asian people with heart disease [20,21]. A diagnosis of coronary heart disease will invariably have psychological, physical and social consequences, which require considerable adjustments from the individual in various life domains [22,23].

In Leicester, a major city in the midlands of the United Kingdom, a significant proportion of the population (around 25\%) is of South Asian origin, almost three quarters of which are Gujarati Indians. Studies exploring the needs and experiences of these people in the first month after MI have found that they reported a lack of information, poor performance of activity, little lifestyle adjustment, poor expectations, lack of future plans, strong family support, dissatisfaction with the family doctor and a significant belief in fate [24,25]. Thus, they appear to have a poor quality of life during convalescence and recovery from MI compared to their white counterparts. However, there is a paucity of empirical data pertaining to the use of validated health-related quality of life measurements in this patient population.

We sought to determine health-related quality of life in a sample of South Asian MI patients at 2 weeks and 3 months after discharge from hospital and to compare them to a matched group of white patients.

\section{Methods}

We studied patients admitted to the 3 coronary care units of Leicester over a 3-month period with a diagnosis of a first acute MI, who were able and willing to give their consent. Ethical approval was obtained from the institutional ethics committee.

Patients were invited by a research nurse to take part in the study. A Gujarati-speaking research nurse was used to recruit the Gujarati Indian patients. All patients were visited at home at 2 weeks and 3 months following discharge from hospital and were asked to complete the Short-Form 36-item health survey (SF-36) and the Hospital Anxiety and Depression Scale (HADS), offered in either a translated Gujarati or English version.

We used the SF-36 [26], judged to be the most reliable quality of life instrument among people with ischaemic heart disease [27,28] and widely used as a measure of health status in patients after MI [28,29]. The SF-36 consists of 8 sub-scales: Physical Functioning (PF), Role- Physical (RP), Bodily Pain (BP), General Health (GH), Vitality (VT), Social Functioning (SF), Role-Emotional (RE) and Mental Health (MH). The PF scale (10 items) reports the extent to which one's health limits physical activities, with low scores suggesting significant limitations in performing all physical activities. The RP scale (4 items) measures the extent to which physical health interferes with work or other daily activities, with the lower scores indicating greater impairment. The BP scale (2 items) measures the intensity of pain, scores range from very severe and extremely limiting pain (low scores) to no pain (high scores). The GH scale (5 items) evaluates one's own perceived health, with low scores indicating poor self-health perceptions. The VT scale (4 items) assesses energy and vitality with low scores representing fatigue and exhaustion. The SF scale (2 items) measures the extent to which physical health or emotional problems affect normal social activities with low scores indicating significant disruption in social activities. The RE scale (3 items) provides an estimate of the degree to which emotional problems disrupt daily activities with low scores indicating greater impairment. The $\mathrm{MH}$ scale (5 items) provides scores that range from significant psychological distress (low scores) to optimal mental health (high scores). A reported Health Transition (HT) scale (1 item) rates health now compared to one year ago.

The SF-36 is a self-administered instrument that takes about 15 minutes to complete. The HADS is the most widely used instrument to assess anxiety and depression and was designed for use in medical settings. It comprises 2 subscales, each of 7 items, used to screen for and measure anxiety and depression. It was used here to screen for the prevalence of anxiety and depression [30,31].

Data were analysed using a 2 (ethnicity) x 2 (observation time) mixed-group analysis of variance (ANOVA) with repeated measures on the second factor. The 2 levels of ethnicity were white (group 1) and South Asian (group 2) and of observation time 2 weeks and 3 months following MI. The dependent variables were subscale domain scores of the SF-36 and the HADS.

\section{Results}

Forty-one white and 41 Gujarati Hindu patients were enrolled into the study and completed the SF-36 and HADS at 2 weeks. Thirty-seven and 39 respectively completed the outcome measures at 3 months. Table 1 shows the demographic characteristics of the participants. The 2 groups were similar in terms of age and sex as intended. They were also similar in terms of marital status. The mean length of residency in the UK for the 
South Asian group was almost 30 years.

Table 1 Demographic characteristics of the sample

\begin{tabular}{lcc}
\hline & Whites & South Asians \\
\hline Male & 32 & 32 \\
Female & 9 & 9 \\
Mean age & 61.2 & 59.9 \\
Mean years living in the UK & - & 28.9 \\
Employed & 16 & 9 \\
Unemployed & 3 & 9 \\
Retired & 16 & 20 \\
Housewife & 3 & 7 \\
Married & 35 & 36 \\
Single & 3 & 1 \\
Widowed & 0 & 4 \\
Divorced & 3 & 0 \\
\hline
\end{tabular}

Table 2 Quality of life of participants at 2 weeks and 3 months. Results are mean (SD) scores

\begin{tabular}{lcccc}
\hline & \multicolumn{2}{c}{ Two weeks } & \multicolumn{2}{c}{ Three months } \\
\hline SF-36 & White & Asian & White & Asian \\
Physical Functioning & & & & \\
Role-Physical & $59.3(22.5)$ & $43.9(24.1)$ & $73.3(19.7)$ & $54.1(27.3)$ \\
Role-Emotional & $20.2(33.2)$ & $14.7(24.1)$ & $65.5(41.3)$ & $37.8(38.8)$ \\
Social Functioning & $42.3(42.7)$ & $21.3(32.8)$ & $60.3(41.4)$ & $50.4(45.8)$ \\
Mental Health & $61.8(24.6)$ & $52.9(31.4)$ & $76.8(23.9)$ & $58.4(31.2)$ \\
Vitality & $66.1(16.7)$ & $56.8(17.8)$ & $72.5(16.3)$ & $59.2(21.8)$ \\
Bodily Pain & $51(14.3)$ & $46.4(21.6)$ & $56.8(18.2)$ & $50.1(22)$ \\
General Health & $66.9(27.6)$ & $56.9(32.3)$ & $75(25.1)$ & $60.4(30.3)$ \\
Health Transition & $58.6(21.9)$ & $51.3(21.1)$ & $63.7(22.6)$ & $54.1(23.4)$ \\
& $36.4(23.2)$ & $29.4(20.5)$ & $51.3(28.8)$ & $40.3(27.2)$ \\
HADS & & & & \\
Anxiety & & & & \\
Depression & $6.75(3.73)$ & $7.37(5.02)$ & $5.42(3.17)$ & $7.12(5.07)$ \\
\hline
\end{tabular}

The mean and standard deviation for each SF-36 and HADS domain are shown in Table 2.

PF scores were higher in the white group than the South Asian group $(p<0.001)$ and higher at 3 months than at 2 weeks $(p<0.001)$.

RP scores were higher in the white group than the South Asian group ( $p=0.01$ ) and higher at 3 months than at

2 weeks $(p<0.001)$. Though there was little difference between groups at 2 weeks, there was a larger difference in favour of the white group at 3 months $(p=0.02)$.

RE scores were higher in the white group than the South Asian group ( $p=0.05)$ and higher at 3 months than at 2 weeks $(p<0.001)$.

SF scores were higher in the white group than the South Asian group ( $p=0.01)$ and higher at 3 months than at 2 weeks $(p<0.001)$.

MH scores were higher in the white group than the Asian group $(p=0.005)$ and higher at 3 months than at 2 weeks $(p<0.01)$.

VT scores were similar for both groups $(p=0.13)$ and only slightly higher at 3 months than at 2 weeks $(p=0.06)$.

BP scores were higher for the White group than the Asian group $(p=0.03)$, but there was no difference over time $(p=0.09)$.

GH scores were similar for both groups $(p=0.09)$ and higher at 3 months than at 2 weeks $(p=0.02)$.

HT scores were similar for both groups $(p=0.08)$ and higher at 3 months than at 2 weeks $(p=0.001)$.

Case detection rates of the HADS anxiety and depression subscales were based on manual convention of subscale scores of 8 or above as possible cases [20].

Fourteen (39\%) of the white and 22 (54\%) of the South Asian group had clinically relevant anxiety at 2 weeks $(p=0.29)$. Eleven (31\%) of the white and $19(46 \%)$ of the South Asian group had clinically relevant anxiety at 3 
months $(p=0.24)$. Anxiety scores were lower at 3 months than at 2 weeks $(p=0.04)$.

Six (17\%) of the white and 15 (37\%) of the South Asian group had clinically relevant depression at 2 weeks $(p=0.09)$. Three (8\%) of the white and $13(32 \%)$ of the South Asian group had clinically relevant depression at 3 months $(p=0.02)$. Depression scores were higher in the Asian group $(p=0.01)$ and were lower in both groups at 3 months than at 2 weeks $(p=0.01)$.

\section{Discussion}

Comparisons of the health-related quality of life of people of mixed ethnic populations are lacking and this is the first study in the UK to determine and compare health-related quality of life in South Asian and white patients after an MI. The findings demonstrate that on all domains of health-related quality of life as assessed by the SF-36, significant improvement occurs in South Asian and white patients following MI over time, a finding consistent with previous investigations of white patients only [32,33]. However, on most SF-36 domains (PF, RP, RE, SF, MH and BP) a significant difference was observed between groups in favour of the white group compared to the South Asian group. This novel finding in an MI population is consistent with a study of Indo-Asian coronary artery bypass surgery patients in the UK, who reported low SF-36 scores for 6 of the 8 domains [34]. However, on one key SF-36 domain, RP, the difference between groups increased significantly at 3 months, lending support to other evidence that South Asian cardiac patients are generally less active than their white counterparts [35-37], indicating that healthier, more active lifestyles should be a priority [38].

The findings regarding the HADS are of interest in that in terms of case classification there are no differences between groups as a function of ethnicity. Though the South Asian group had higher depression scores than the white group, this finding must be viewed within the context of case identification parameters of the HADS. The HADS was never conceived as an instrument to accurately measure depression in a linear way, it is simply a case detector. Consequently, though the observation of group differences is tantalising, the finding that there are no group differences in terms of case classification takes precedence with the interpretation of this particular instrument. Thus, it can be concluded that there is no evidence of ethnic group differences in terms of HADS-assessed anxiety and depression though observation of significant differences in absolute scores on the depression subscale would suggest further exploration of this issue is warranted.

\section{Conclusion}

Our findings indicate that South Asians have significantly poorer quality of life after an MI than white people. Further research is required to determine the factors accounting for differential quality of life outcomes as a function of ethnicity following MI. This would seem to be a priority in terms of developing models of care for delivering the most effective and culturally sensitive interventions to this group.

\section{Conflicts of Interest}

No funding was received for this study and the authors have no conflicts of interest to declare.

\section{References}

[1] McKeigue, P.M., Miller, G. \& Marmot, M. (1989). Coronary heart disease in south Asians overseas: a review. Journal of Clinical Epidemiology 42 (7) 597-609.

[2] Wilkinson, P. Sayer, J. Laji, K., Grundy, C., Marchant, B., Kopelman, P. \& Timmis, A.D. (1996). Comparison of case fatality in south Asian and white patients after acute myocardial infarction: observational study. British Medical Journal 312 (7042) 1330-1333.

[3] Zhang, Z-M., Rautaharju, P.M., Prineas, R.J., Rodriguez, C.J., Loehr, L., Rosamond, W.D., Kitzman, D., Couper, D. \& Soliman, E.Z. (2016). Race and Sex Differences in the Incidence and Prognostic Significance of Silent Myocardial Infarction in the Atherosclerosis Risk in Communities (ARIC) Study. Circulation 133 (22) 2141- 2148.

[4] Chaturvedi, N. (2003). Ethnic differences in cardiovascular disease. Heart 89 (6) 681-686.

[5] Eriksen, A., Tillin, T., O’Connor, L., Brage, S., Hughes, A., Mayet, J., McKeique, P., Whincup, P., Chaturvedi, N. \& Foroughi, N.G. (2015). The impact of health behaviours on incident cardiovascular 
disease in Europeans and South Asians - a prospective analysis in the UK SABRE study. PloS One 10 (3) e0117364.

[6] Tillin, T., Dhutia, H., Chambers, J., Malik, I., Coady, E., Mayet, J., Wright, A.R., Kooner, J., Shore, A., Thom, S., Chaturvedi, N. \& Hughes, A. (2008). South Asian men have different patterns of coronary artery disease when compared with European men. International Journal of Cardiology 129 (3) 406-413.

[7] Weir-McCall, J.R., Cassidy, D.B., Belch, J.J.F., Gandy, S.J., Houston, J.G., Lambert, M.A., Littleford, R.C., Rowland, J., Struthers, A.D. \& Khan, F. (2016). Whole- body cardiovascular MRI for the comparison of atherosclerotic burden and cardiac remodelling in healthy South Asian and European adults. British Journal of Radiology 89 (1065) 20160342.

[8] Ben-Shlomo, Y., Naqvi, H. \& Baker, I. (2008). Ethnic differences in healthcare-seeking behaviour and management for acute chest pain: secondary analysis of the MINAP dataset 2002-2003. Heart 94 (3) 354-359.

[9] Wechkunanukul, K., Grantham, H. Damarell, R. \& Clark, R.A. (2016). The association between ethnicity and delay in seeking medical care for chest pain: a systematic review. JBI Database of Systematic Reviews and Implementation Reports 14 (7) 208-235.

[10] Galdas, P., Cheater, F. \& Marshall, P. (2007). What is the role of masculinity in white and South Asian men's decisions to seek medical help for cardiac chest pain? Journal of Health Services Research \& Policy 12 (4) 223- 229.

[11] Kendall, H., Marley, A., Patel, J.V., Khan, J.M., Blann, A.D., Lip, G.Y. \& Dwivedi, G. (2013). Hospital delay in South Asian patients with acute ST-elevation myocardial infarction in the UK. European Journal of Preventive Cardiology 20 (5) 737-742.

[12] Sekhri, N., Timmis, A., Hemingway, H., Walsh, N., Eldridge, S., Junghans, C. \& Feder, G. (2012). Is access to specialist assessment of chest pain equitable by age, gender, ethnicity and socioeconomic status? An enhanced ecological analysis. BMJ Open 2 (3) e001025.

[13] Shaukat, N., De Bono, D. \& Cruickshank, J. (1993). Clinical features, risk factors, and referral delay in British patients of Indian and European origin with angina matched for age and extent of coronary atheroma. British Medical Journal 307 (6906) 717.

[14] Grewal, K., Leung, Y.W., Safai, P., Stewart, D.E., Anand, S., Gupta, M., Parsons, C. \& Grace, S.L. (2010). Access to cardiac rehabilitation among South-Asian patients by referral method: a qualitative study. Rehabilitation Nursing 35 (3) 106-112.

[15] Lear, J., Lawrence, I., Burden, A. \& Pohl, J. (1994). A comparison of stress test referral rates and outcome between Asians and Europeans. Journal of the Royal Society of Medicine 87 (11) 661-662.

[16] Barakat, K., Wells, Z., Ramdhany, S., Mills, P. \& Timmis, A. (2003). Bangladeshi patients present with non- classic features of acute myocardial infarction and are treated less aggressively in east London, UK. Heart 89 (3) 276-279.

[17] Lear, J., Lawrence, I., Pohl, J. \& Burden, A. (1993). Myocardial infarction and thrombolysis: a comparison of the Indian and European populations on a coronary care unit. Journal of the Royal College of Physicians of London 28 (2) 143-147.

[18] Feder, G., Crook, A.M., Magee, P., Banerjee, S., Timmis, A.D. \& Hemingway, H. (2002). Ethnic differences in invasive management of coronary disease: prospective cohort study of patients undergoing angiography. British Medical Journal 324 (7336) 511-516.

[19] Sekhri, N., Timmis, A., Chen, R., Junghans, C., Walsh, N., Zaman, J., Eldridge, S., Hemingway, H. \& Feder, G. (2008). Inequity of access to investigation and effect on clinical outcomes: prognostic study of coronaryangiography for suspected stable angina pectoris. British Medical Journal 336 (7652) 10581061.

[20] Scheppers, E., Van Dongen, E., Dekker, J., Geertzen, J. \& Dekker, J. (2006). Potential barriers to the use of health services among ethnic minorities: a review. Family Practice 23 (3) 325-348.

[21] Garrett, C.R., Gask, L.L., Hays, R., Cherrington, A., Bundy, C., Dickens, C., Waheed, W. \& Coventry, P.A. (2012). Accessing primary health care: a meta-ethnography of the experiences of British South Asian patients with diabetes, coronary heart disease or a mental health problem. Chronic Illness 8 (2) 135-155.

[22] Bhattacharyya, M., Stevenson, F. \& Walters, K. (2016). Exploration of the psychological impact and adaptation to cardiac events in South Asians in the UK: a qualitative study. BMJ Open 6 (7) e010195.

[23] Leon, A.S., Franklin, B.A., Costa, F., Balady, G.J., Berra, K.A., Stewart, K.J., Thompson, P.D., Williams, M.A. \& Lauer, M.S. (2005). Cardiac rehabilitation and secondary prevention of 
coronary heart disease an American Heart Association scientific statement from the council on clinical cardiology (subcommittee on exercise, cardiac rehabilitation, and prevention) and the council on nutrition, physical activity, and metabolism (subcommittee on physical activity), in collaboration with the American association of cardiovascular and pulmonary rehabilitation. Circulation 111 (3) 369-376.

[24] Webster, R. (1996). The experiences and health care needs of Asian coronary patients and their partners. Methodological issues and preliminary findings. Nursing in Critical Care 2 (5) 215-223.

[25] Webster, R.A., Thompson, D.R. \& Mayou, R.A. (2002). The experiences and needs of Gujarati Hindu patients and partners in the first month after a myocardial infarction. European Journal of Cardiovascular Nursing 1 (1) 69-76.

[26] Ware, J.E., Kosinski, M., Dewey, J.E. \& Gandek, B. (2000). SF-36 health survey: manual and interpretation guide. Lincoln, RI, USA: Quality Metric Inc.

[27] Dempster, M. \& Donnelly, M. (2001). A Comparative Analysis of the SF-12 and the SF-36 among Ischaemic Heart Disease Patients. Journal of Health Psychology 6 (6) 707-711.

[28] Huber, A., Oldridge, N. \& Höfer, S. (2016). International SF-36 reference values in patients with ischemic heart disease. Quality of Life Research 25 (11) 2787-2798.

[29] Brown, N., Melville, M., Gray, D., Young, T., Munro, J., Skene, A. \& Hampton, J. (1999). Quality of life four years after acute myocardial infarction: short form 36 scores compared with a normal population. Heart 81 (4) 352-358.

[30] Zigmond, A.S. \& Snaith, R.P. (1983). The hospital anxiety and depression scale. Acta Psychiatrica Scandinavica 67 (6) 361-370.

[31] Snaith, R. \& Zigmond, A. (1986). The hospital anxiety and depression scale. British Medical Journal 292 (6516) 344.

[32] Brink, E., Grankvist, G., Karlson, B.W. \& Hallberg, L.R-M. (2005). Health-related quality of life in women and men one year after acute myocardial infarction. Quality of Life Research 14 (3) 749-757.

[33] Bengtsson, I., Hagman, M., Währborg, P. \& Wedel, H. (2004). Lasting impact on health-related quality of life after a first myocardial infarction. International Journal of Cardiology 97 (3) 509-516.

[34] Goldsmith, I., Lip, G., Kumar, P. \& Patel, R. (1998). A survey of hospital morbidity, mortality and quality of life following coronary artery bypass surgery in a UK Indo-Asian population. International Journal of Clinical Practice 53 (1) 9-14.

[35] Lip, G.Y., Cader, M.Z., Lee, F., Munir, S.M. \& Beevers, D.G. (1996). Ethnic differences in preadmission levels of physical activity in patients admitted with myocardial infarction. International Journal of Cardiology 56 (2) 169-175.

[36] Dhanjal, T., Lal, M., Haynes, R. \& Lip, G. (2001). A comparison of cardiovascular risk factors among Indo- Asian and caucasian patients admitted with acute myocardial infarction in Kuala Lumpur, Malaysia and Birmingham, England. International Journal of Clinical Practice 55 (10) 665-668.

[37] Williams, E.D., Stamatakis, E., Chandola, T. \& Hamer, M. (2011). Physical activity behaviour and coronary heart disease mortality among South Asian people in the UK: an observational longitudinal study. Heart 97 (8) 655-659.

[38] Zaman, M.J.S. \& Jemni, M. (2011). South Asians, physical exercise and heart disease. Heart 97 (8) 607609. 